\title{
BMJ Open Association of lifestyle factors and suboptimal health status: a cross- sectional study of Chinese students
}

\author{
Jianlu Bi, ${ }^{1,2}$ Ying Huang, ${ }^{1,2}$ Ya Xiao, ${ }^{1,2}$ Jingru Cheng, ${ }^{1,2}$ Fei Li, ${ }^{1,2}$ Tian Wang, ${ }^{1,2}$ \\ Jieyu Chen, ${ }^{1,2}$ Liuguo Wu, ${ }^{1,2}$ Yanyan Liu, ${ }^{3}$ Ren Luo, ${ }^{1,2}$ Xiaoshan Zhao ${ }^{1,2}$
}

To cite: Bi J, Huang Y, Xiao $\mathrm{Y}$, et al. Association of lifestyle factors and suboptimal health status: a cross-sectional study of Chinese students. BMJ Open 2014;4:e005156.

doi:10.1136/bmjopen-2014005156

- Prepublication history for this paper is available online. To view these files please visit the journal online (http://dx.doi.org/10.1136/ bmjopen-2014-005156).

$\mathrm{JB}$ and $\mathrm{YH}$ contributed equally to this work.

Received 19 March 2014 Revised 17 May 2014 Accepted 23 May 2014

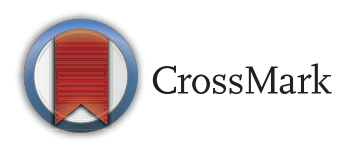

\footnotetext{
${ }^{1}$ Department of Traditional Chinese Medicine, Nanfang Hospital, Southern Medical University, Guangzhou, Guangdong, China ${ }^{2}$ School of Traditional Chinese Medicine, Southern Medical University, Guangzhou, Guangdong, China

${ }^{3}$ Department of Rheumatic diseases, The First Affiliated Hospital of Guangzhou University of Chinese Medicine, Guangzhou, China
}

\section{Correspondence to}

Ren Luo;

luoren41671@aliyun.com and Dr Xiaoshan Zhao; zhaoxs0609@163.com

\section{ABSTRACT}

Objectives: Suboptimal health status (SHS) is considered to be an intermediate status between disease and health, and is characterised by a decline in vitality, in physiological function and in the capacity for adaptation. Although the incidence of SHS is high, the underlying causes remain unclear. Lifestyle is one of the most important factors affecting health status; however, the relationship between SHS and lifestyle has not been elucidated.

Design: Cross-sectional survey.

Setting: A questionnaire, based on 'Health Promoting Lifestyle Profile-II (HPLP-II)' and 'Sub-Health Measurement Scale V1.0 (SHMS V1.0)', was sent to four colleges in four districts (Guangzhou, Foshan, Zhanjiang and Shaoguan) of China between May and July 2013.

Participants: A total of 12429 questionnaires were distributed during the study period, and 11144 completed responses were received.

Results: The prevalence rates for the 'healthy', 'SHS' and 'disease' groups of respondents (students) were 22.81\% (2542), $55.9 \%$ (6234) and $21.25 \%$ (2368), respectively. Most of the students reported a 'moderate' or 'good' lifestyle. There were significant differences in lifestyle and health status between the two genders. It was notable that health status was significantly positively correlated with lifestyle ( $r=0.563)$. For every dimension of the HPLP-II model, the mean values were lower for those participants who reported as 'SHS' or 'disease' than for those who reported that they were 'healthy'. The individual dimensions of the HPLP-II model, including 'spiritual growth', 'health responsibility', 'physical activity', 'interpersonal relations' and 'stress management' were all related to SHS.

Conclusions: Health status is significantly positively correlated with lifestyle. Poor lifestyle is a risk factor for SHS. Conversely, adopting a healthier lifestyle can improve SHS.

Trial registration number: ChiCTR-OCH-12002317.

\section{INTRODUCTION}

Suboptimal health status (SHS) is considered to be an intermediate status between disease and health. In the traditional Chinese medicine guidelines released by the China

\section{Strengths and limitations of this study}

- The prevalence rate of suboptimal health status (SHS) is $55.9 \%$ in Chinese students by a crosssectional study.

- Health status is significantly positively correlated with lifestyle.

- Poor lifestyle is a risk factor for SHS; conversely, adopting a healthier lifestyle can improve SHS.

Association of Chinese Medicine (CACM), it is characterised by a decline in vitality, in physiological function and in the capacity for adaptation. ${ }^{1-3}$ Over the years, the concept of SHS has been widely accepted in many other countries, including Japan, ${ }^{4}$ Canada and Australia. ${ }^{5}$ According to a survey of civil servants undertaken by ourselves, SHS was applicable to $65.1 \%$ of the total survey population $^{7}$; although the incidence of SHS is high, the causes remain unclear.

Lifestyle is one of the most important factors affecting health. ${ }^{8-11}$ To achieve the goal of a healthy population worldwide requires action in disease prevention as well as health promotion. Health-promoting lifestyles are a "multidimensional pattern of self-initialed actions and perceptions that serve to maintain or enhance the level of wellness, self-actualization, and fulfillment of the individual." ${ }^{12}$ Working on this basis, Walker et $a l^{12}$ developed the Health Promoting Lifestyle Profile (HPLP) to describe an individual's health promotion lifestyle. HPLP has since been translated into several languages, and it is used widely to study lifestyle and health status. ${ }^{13-18}$

A number of previous studies have proposed that SHS may be related to poor lifestyle habits, such as going to bed late, work-related and study-related stress, physical inactivity and poor diet pattern. ${ }^{17}{ }^{19-22}$ In the work reported here, we have studied the relationship between SHS and lifestyle factors using the Chinese version of HPLP-II (translated by Yen) ${ }^{15}$ 


\section{METHODS}

\section{Survey instruments}

A cross-sectional study was conducted among four colleges in four areas of China (Guangzhou, Foshan, Zhanjiang and Shaoguan). Data were collected between May and July 2013. A questionnaire, which sought information on sociodemographic indicators and which included 'HPLP-II' and 'Sub-Health Measurement Scale V1.0 (SHMS V1.0)', was used to assess the respondents' health status and lifestyle. The questionnaire was completed by each volunteer within $30 \mathrm{~min}$. Verbal consents were deemed to be sufficient because the students had volunteered for the study and could refuse to take part if they wished. The objective of the survey was to study the students' health status rather than to intervene. All student data were kept strictly confidential. The ethics committee also approved the consent procedure.

\section{SHS evaluation}

The evaluation of SHS was performed according to the clinical guidelines for SHS published by the CACM. ${ }^{2}$ Participants completed the SHMS V1.0, which is a multidimensional, self-report symptom inventory that has been developed by our research group in China. ${ }^{23}$ SHMS V1.0 consists of 39 items in total, 35 of which are divided among three symptom dimensions (physiological, psychological and social and 10 factors, as indicated in table 1. Thus, the physiological dimension comprises the following factors: physical condition (three items), organ function (six items), body movement function (three items) and vigour (two items); the psychological dimension comprises: positive emotion (four items), psychological symptoms (six items) and cognitive function (two items); and the society dimension comprises: social adjustment (four items), social resources (three items) and social support

\begin{tabular}{|c|c|c|c|}
\hline Dimension & Factors & Items & $\begin{array}{l}\text { Item } \\
\text { distribution }\end{array}$ \\
\hline \multirow[t]{4}{*}{ Physiological } & $\begin{array}{l}\text { Physical } \\
\text { condition }\end{array}$ & 3 & $1,2,3$ \\
\hline & Organ function & 6 & $4,5,6,7,8,9$ \\
\hline & $\begin{array}{l}\text { Body movement } \\
\text { function }\end{array}$ & 3 & $10,11,12$ \\
\hline & Vigour & 2 & 13,14 \\
\hline \multirow[t]{3}{*}{ Psychological } & Positive emotion & 4 & $16,17,18,19$ \\
\hline & $\begin{array}{l}\text { Psychological } \\
\text { symptoms }\end{array}$ & 6 & $\begin{array}{l}20,21,22,23 \\
24,25\end{array}$ \\
\hline & $\begin{array}{l}\text { Cognitive } \\
\text { function }\end{array}$ & 2 & 26,27 \\
\hline \multirow[t]{3}{*}{ Social } & $\begin{array}{l}\text { Social } \\
\text { adjustment }\end{array}$ & 4 & $29,30,31,32$ \\
\hline & Social resources & 3 & $33,34,35$ \\
\hline & Social support & 2 & 36,37 \\
\hline Healthy evaluation & & 4 & $15,28,38,39$ \\
\hline Total & & 39 & \\
\hline
\end{tabular}

(two items). A final dimension, healthy evaluation, comprises four further items. For each item, there are five response categories (defined as 'none', 'occasionally', 'sometimes', 'constantly' and 'always') corresponding, respectively, to the frequency of occurrence of each symptom. In the data analysis, 'none' was assigned a score of 1, 'occasionally' 2, 'sometimes' 3 , 'constantly' 4 and 'always' 5. Participants were asked about uncomfortable symptoms that they had experienced during the previous month. The total scores were then calculated. A low total score represents a low estimate of SHS (ie, poor health).

Before the survey, the students had attended an annual school health examination in hospital. The health examination included medical history, a physical examination, blood haematology and biochemistry analyses, rest ECG and chest radiography. After excluding any participants who were diagnosed with clinical disease in the health examination, the threshold values for SHS in the physiological, psychological and society dimensions of SHMS V1.0 were 68,67 and 67 , respectively. If participants were not in SHS with respect to any of these three dimensions (physiological, psychological and society), they were considered healthy. The threshold values were determined by the SHS Branch of the CACM in Guangdong. The validity and reliability of SHMS V1.0 has been confirmed, with a Cronbach $\alpha$ and split-half reliability coefficients of 0.917 and 0.831 , respectively. ${ }^{23}$

\section{Lifestyle evaluation}

The Chinese version of HPLP-II is a translation from the English undertaken by $\mathrm{Yen}^{15}$; it is a revised 52-item instrument that includes six dimensions: 'health responsibility' (nine items), 'physical activity' (eight items), 'nutrition' (nine items), 'spiritual growth' (nine items), 'interpersonal relations' (nine items) and 'stress management' (eight items). The names of three of the six original dimensions have been altered (thus, 'self-actualisation' has been altered to 'spiritual growth', 'interpersonal support' to 'interpersonal relations' and 'exercise' to 'physical activity'). ${ }^{15}$ Respondents were asked to report their behaviours on a four-point Likert scale $(1=$ never, $2=$ sometimes, $3=$ often and $4=$ routinely). Following the recommendations of the original authors of the scale, the overall HPLP-II score was obtained by calculating the mean of the responses to all 52 items. HPLP-II scores therefore ranged between 52 and 208. The healthpromoting lifestyle scores were divided into four levels: 52-90 designated 'poor', 91-129 'moderate', 130-168 'good' and 169-208 'excellent'. Higher scores indicated a greater frequency of health-promoting behaviours.

\section{Statistical analyses}

Data are reported as the mean \pm SD for continuous variables, or as frequencies in the case of categorical variables. Descriptive statistics and univariate analyses were carried out using SPSS V13.0 (SPSS Inc, Chicago, Illinois, USA). Pearson $\chi^{2}$ tests and independent-sample $\mathrm{t}$ tests were used to compare the independent variables 
versus dependent variables, and the corresponding $95 \%$ CIs were calculated. $\mathrm{p}$ Value $<0.05$ was considered to be significant for all tests.

\section{RESULTS}

A total of 12429 questionnaires (including requests for sociodemographic information, and the documents HPLP-II and SHMS V1.0) were distributed during the study period, and 11144 completed responses were received (a response rate of $89.66 \%$ ).

\section{Lifestyle condition by gender}

A total of 11144 students aged 18-26 years (mean age 20.70 years, $\mathrm{SD}=1.58$ ) were analysed. There were 4780 men and 6363 women. Table 2 shows the Student' t test results of different levels of HPLP-II by gender. The numbers of students at the 'poor', 'moderate', 'good' and 'excellent' levels were 309, 5814, 4587 and 434, respectively. Most students reported 'moderate' or 'good' lifestyles. There were significant differences between men and women at the 'poor', 'moderate' and 'good' levels, but no significant difference at the 'excellent' level. The mean scores for women at the 'poor' and 'moderate' levels were higher than the corresponding scores for men, and the mean scores for women at the 'good' and 'excellent' levels were lower than those calculated for men $(\mathrm{p}=0.000)$.

\section{Overall student health status}

A total of 11144 students were evaluated, and the numbers of students in the 'healthy', 'SHS' and 'disease' groups were 2542, 6234 and 2368, respectively. The prevalence rate of SHS was $55.9 \%$ (6234). The major diseases that were reported affected the respiratory and digestive systems, such as chronic rhinitis (1074), chronic gastritis (320), chronic pharyngitis (317), piles (109), chronic bronchitis (76) and gastroduodenal ulcer (75). The mean scores and SD values for the individual dimensions of SHMS V1.0, and for the SHMS V1.0 data overall, are shown in table 3 . There were significant differences between the 'healthy', 'SHS' and 'disease' groups with respect to the physiological, psychological and society dimensions $(p=0.000)$. The mean scores of the participants in the 'healthy' group were significantly higher than those of the participants in the 'SHS' and 'disease' groups $(\mathrm{p}=0.000)$.

\begin{tabular}{lccrr} 
Table 2 & \multicolumn{2}{l}{ Lifestyle condition by gender } & & \\
\cline { 1 - 3 } $\begin{array}{l}\text { HPLP-II } \\
\text { level }\end{array}$ & HPLP-II scores & & \\
\cline { 2 - 3 } Male & \multicolumn{1}{c}{ Female } & t & p Value \\
\hline Poor & $81.42 \pm 7.82$ & $83.67 \pm 6.79$ & 2.598 & 0.010 \\
Moderate & $113.90 \pm 9.97$ & $115.65 \pm 9.63$ & 6.736 & 0.000 \\
Good & $143.47 \pm 10.06$ & $142.85 \pm 9.83$ & -2.075 & 0.038 \\
Excellent & $182.6 \pm 11.74$ & $180.80 \pm 11.09$ & -1.651 & 0.099 \\
\hline HPLP, Health Promoting Lifestyle Profile. & &
\end{tabular}

The number of men in the 'healthy', 'SHS' and 'disease' groups were 1169, 2698 and 913, whereas the number of women were 1373, 3536 and 1454, respectively. The mean scores for the individual dimensions of SHMS V1.0 were higher in men than in women (table 3); and there were statistically significant differences between men and women $(p=0.000)$. The results suggest that the health status of female students is poorer than that of their male counterparts.

\section{The health status of students by HPLP-II level}

As shown in table 4, the mean scores as determined using SHMS V1.0 increased in line with the transition from the 'poor' level to the 'excellent' level according to HPLP-II; they were significantly positively correlated (Spearman's $\mathrm{r}=0.563, \mathrm{p}=0.000$; figure 1 ). The statistics in table 5 show that most students at the 'good' HPLP-II level were 'healthy' students, while those at the 'moderate' HPLP-II level were in the 'SHS' and 'disease' categories, and this difference was statistically significant $\left(\chi^{2}=1640.444, p=0.000\right)$.

\section{Comparative analysis of HPLP-II scores by health status}

Table 6 shows the mean score and SD for each HPLP-II dimension. There were statistically significant differences between the 'healthy', 'SHS' and 'disease' groups $(p=0.000)$. For each of the HPLP-II dimensions, the mean scores for the 'SHS' and 'disease' groups were lower than those for the 'healthy' group, indicating that students in the two former groups had poorer lifestyles.

\section{Logistic regression analysis of SHS and lifestyle}

Table 7 shows the regression analysis parameter estimates and SEs for lifestyle and health and SHS. For HPLP-II, five of the dimensions ('spiritual growth', 'health responsibility', 'physical activity', 'interpersonal relations' and 'stress management') were entered into the stepwise regression equation.

\section{DISCUSSION}

The aim of this study was to examine the relationship between health status and lifestyles so as to obtain a more complete profile of the well-being of students and to identify more effective intervention measures. We found that the prevalence rate of SHS was $55.9 \%$ (6234/ $11494)$. This result is similar to other reports from China. ${ }^{24}{ }^{25}$ Most students reported a 'moderate' lifestyle. Notably, health status was significantly positively correlated with lifestyle $(r=0.563)$. The mean values for the 'SHS' and 'disease' groups were lower than those for the 'healthy' group for every dimension of the HPLP-II model. Our findings also revealed that 'physical activity', 'health responsibility', 'spiritual growth', 'interpersonal relations' and 'stress management' are all related to SHS.

In 1946, the WHO defined health in its broader sense as "a state of complete physical, mental, and social well- 
Table 3 SHMS V1.0 scores by health status

\begin{tabular}{|c|c|c|c|c|c|}
\hline & Healthy & SHS & Disease & $\mathbf{F}$ & p Value \\
\hline \multicolumn{6}{|c|}{ Dimensions of SHMS V1.0 } \\
\hline Physiological & $82.3 \pm 6.91$ & $70.91 \pm 9.55$ & $69.84 \pm 10.34$ & 1592.251 & 0.000 \\
\hline Psychological & $78.27 \pm 7.00$ & $60.73 \pm 10.27$ & $62.29 \pm 12.61$ & 2784.864 & 0.000 \\
\hline Society & $79.47 \pm 7.30$ & $60.73 \pm 11.85$ & $64.95 \pm 13.73$ & 2434.389 & 0.000 \\
\hline \multicolumn{6}{|l|}{ Gender } \\
\hline Male & $81.16 \pm 5.60$ & $65.45 \pm 8.03$ & $66.45 \pm 10.60$ & 1616.441 & 0.000 \\
\hline Female & $79.36 \pm 4.98$ & $64.31 \pm 7.45$ & $65.71 \pm 9.53$ & 2043.924 & 0.000 \\
\hline Total & $80.19 \pm 5.35$ & $64.8 \pm 7.73$ & $65.99 \pm 9.96$ & 3666.607 & 0.000 \\
\hline
\end{tabular}

being and not merely the absence of disease or infirmity." ${ }^{26}$ With greater understanding of health, the definition has deepened to take account of SHS, which is an intermediate state between disease and health, as proposed by Wang. ${ }^{1} 27$ Prevention and intervention strategies aimed at SHS are similar to the concept of preventive, predictive and personalised medicine, which is an effective approach to the improvement of health, the prevention of disease and the treatment of early-stage illness. ${ }^{13}$ The results presented in this study revealed that the prevalence rate of SHS was high $(55.9 \%)$. Although the prevalence of suboptimal health is high, there has been a lack of objective clinical diagnostics for SHS. A number of SHS questionnaires have been established and evaluated in China, such as Suboptimal Health Status Questionnaire (SHSQ)-25 and Multidimensional Subhealth Questionnaire of Adolescents (MSQA) ${ }^{20}{ }^{28}$; however, Suboptimal Health Status Questionnaire (SHSQ)-25 is targeted at physiological and psychological SHS and MSQA is aimed at adolescents. SHMS V1.0, on the other hand, is a multidimensional questionnaire that includes physiological, psychological and social dimensions. ${ }^{23}$ As they enter young adulthood, a number of students appear with physical, psychological and social problems; hence, SHMS V1.0 is very suitable for the assessment of the health status of students.

Unhealthy behaviours and lifestyles are two important factors that are associated with 10 major causes of death. $^{8-11}$ Lifestyle is reportedly associated with increased risks of gastroduodenal ulcer, ${ }^{29}$ chronic rhinitis, ${ }^{30}$ obesity, ${ }^{31}$ neck cancer, ${ }^{32}$ breast cancer ${ }^{33}$ and coronary heart disease, ${ }^{34}$ and 'lifestyle diseases' are an

Table 4 SHMS V1.0 scores for each HPLP-II level

\begin{tabular}{lc}
\hline HPLP-II level & SHMS V1.0 scores (mean \pm SD) \\
\hline Poor & $57.18 \pm 11.28$ \\
Moderate & $64.8 \pm 8.93$ \\
Good & $72.9 \pm 8.25$ \\
Excellent & $81.28 \pm 8.75$ \\
\hline HPLP, Health Promoting Lifestyle Profile; SHMS, Sub-Health \\
Measurement Scale.
\end{tabular}

increasing threat to health. Comprehensive lifestyle changes may have therapeutic potential in early cancers, ${ }^{35}$ diabetes ${ }^{36}$ and stroke. ${ }^{37}$ The findings of the present study suggested that students affected by disease had poor lifestyles. The types of diseases in question largely affected the respiratory and digestive systems, which are closely related to lifestyle. ${ }^{30} 31$ There are therefore opportunities for individuals to make changes to poor lifestyle factors and to improve their health status as a result.

Previous studies have proposed that SHS may be related to poor lifestyle factors, such as going to bed late, work-related and study-related stress, physical inactivity and poor diet. ${ }^{1} \quad \begin{array}{llll}19-22 & 38 & \text { This study was }\end{array}$ designed to assess the relationship between lifestyle and health status. The statistical analysis revealed that health status was significantly positively correlated with lifestyle. SHS and disease students reported poor lifestyles. Lifestyle factors affect a range of aspects of health status -physiological, psychological and social. Within the framework of HPLP-II, 'physical activity' and 'nutrition' may affect physiological health, 'spiritual growth' and

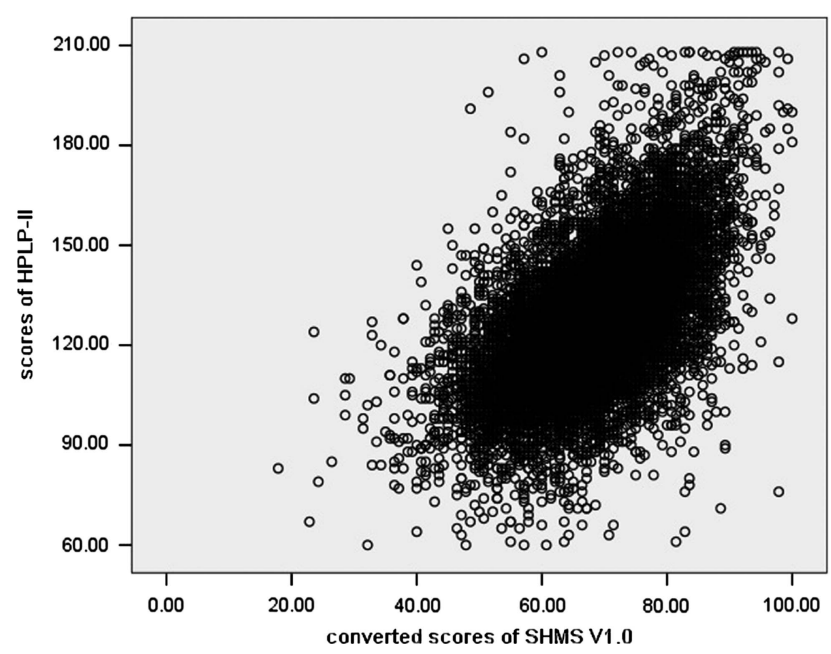

Figure 1 Scatter plot of Sub-Health Measurement Scale (SHMS) V1.0 scores and Health Promoting Lifestyle Profile (HPLP)-II scores. 
Table 5 Frequencies of health status categories, for each HPLP-II level

\begin{tabular}{lrrrrl}
\hline HPLP-II & & & & & $p$ \\
level & Healthy & SHS & Disease & $\chi^{2}$ & Value \\
\hline Poor & 11 & 237 & 61 & 1640.444 & 0.000 \\
Moderate & 579 & 3960 & 1275 & & \\
Good & 1663 & 1957 & 967 & & \\
Excellent & 289 & 80 & 65 & &
\end{tabular}

HPLP, Health Promoting Lifestyle Profile; SHS, suboptimal health status.

'stress management' influence psychological health and interpersonal relations impact on social health. In addition, our results (tables 3 and 6) indicated that the SHMS V1.0 and HPLP-II scores for the 'SHS group' were generally lower than those for the other two groups ('healthy' and 'disease'). Students affected by diseases may worry about their health status and do their best to improve the symptoms and physical signs. They may change their lifestyle, exercise more and actively treat the disease, which can improve their health status. SHS students, on the other hand, do not pay increased attention to their lifestyle, which as a result continues to harm their health. Most generally, due to heavy study loads and anxiety, most students do not eat regularly, get sufficient sleep or exercise adequately; and as a result, they may suffer from headaches, insomnia, fatigue and forgetfulness. It is therefore important to focus attention on SHS and lifestyle factors that threaten the health of young people.

Our study also revealed that men and women show significant differences in lifestyle as well as health status. Men and women have different morphological, physiological, metabolic and genetic characteristics. It is reported that women are more prone to depression, anxiety and other neuropsychiatric disorders. ${ }^{39} 40$ This may be because women are more influenced by pressure, and by their surroundings and experiences, which might make them more prone to SHS.

Poor lifestyle is detrimental to personal health. The current health status of today's students may provide an insight into their likely performance as professional workers in the future. Therefore, an understanding of the variables that can affect the health profiles of students warrants serious attention.

\section{CONCLUSION}

Health status is significantly positively correlated with lifestyle. Poor lifestyle is a risk factor for SHS. Conversely, adopting a healthier lifestyle can improve SHS.

\section{LIMITATIONS}

Some limitations should be noted. First, this was a crosssectional design, which did not allow us to assess causality or the directionality of relationships. Second, all information was obtained from self-reported questionnaires, which could result in potential information bias.

Table 6 Scores for each HPLP-II dimension, according to health status

\begin{tabular}{lcccccc}
\hline HPLP-II dimensions & Number of items & $\begin{array}{l}\text { Healthy } \\
\text { (mean } \pm \text { SD) }\end{array}$ & SHS (mean \pm SD) & Disease (mean \pm SD) & F & p Value \\
\hline Spiritual growth & 9 & $29.10 \pm 4.33$ & $23.97 \pm 4.74$ & $25.34 \pm 4.92$ & 1081.539 & 0.000 \\
Health responsibility & 9 & $19.91 \pm 5.09$ & $16.68 \pm 3.95$ & $17.39 \pm 4.11$ & 520.067 & 0.000 \\
Physical activity & 8 & $19.88 \pm 4.4 .99$ & $16.58 \pm 4.35$ & $16.88 \pm 4.47$ & 498.864 & 0.000 \\
Nutrition & 9 & $23.23 \pm 4.64$ & $20.40 \pm 4.14$ & $21.18 \pm 4.25$ & 392.236 & 0.000 \\
Interpersonal relations & 9 & $27.87 \pm 4.14$ & $23.75 \pm 4.19$ & $25.11 \pm 4.33$ & 866.506 & 0.000 \\
Stress management & 8 & $24.33 \pm 3.74$ & $20.59 \pm 3.61$ & $21.41 \pm 3.81$ & 935.300 & 0.000 \\
Total scale & 52 & $144.31 \pm 20.58$ & $121.96 \pm 18.61$ & $127.29 \pm 19.44$ & 1219.263 & 0.000 \\
\hline
\end{tabular}

Table 7 Stepwise regression variables

\begin{tabular}{lllllll}
\hline Variables & & & & & \multicolumn{2}{c}{$\mathbf{9 5 \%}$ CI for OR } \\
\hline Spiritual growth & B & SE & p Value & OR & Lower & Upper \\
Health responsibility & -0.142 & 0.008 & 0.000 & 0.867 & 0.854 \\
Physical activity & -0.017 & 0.008 & 0.034 & 0.983 & 0.968 & 0.881 \\
Interpersonal relations & -0.032 & 0.007 & 0.000 & 0.969 & 0.955 & 0.983 \\
Stress management & -0.062 & 0.009 & 0.000 & 0.94 & 0.923 & 0.958 \\
\hline
\end{tabular}


Figure 2 Sub -Health Measurement Scale V1.0

Please read the questions below and fill in your answers referring to the previous 4 weeks.

\begin{tabular}{|c|c|c|c|c|c|}
\hline 1. How about your appetite? & $\square$ very poor & $\square$ poor & $\square$ general & $\square$ good & $\square$ very good \\
\hline 2. How about your sleep? & $\square$ very poor & $\square$ poor & $\square$ general & $\square$ good & $\square$ very good \\
\hline $\begin{array}{l}\text { 3. Are you satisfied with your hair growth? (eg, early white hair, } \\
\text { yellow hair or hair loss, etc) }\end{array}$ & $\square$ never & $\square$ little & $\square$ general & $\square$ good & $\square$ very good \\
\hline
\end{tabular}

4. Do you suffer from palpitations, chest tightness, or shortness of breath?

5. Do you suffer from gastrointestinal discomfort? (eg, acid reflux,
belching, nausea, abdominal pain, bloating, diarrhoea,

$\square$ never $\quad \square$ occasionally $\square$ sometimes $\square$ constantly $\square$ always

constipation, etc)

6. Do you suffer from abnormal urine? (eg, dark urine, dysuria, oliguria, urinary frequency, nocturia, etc)

7. Do you suffer from head discomfort? (eg, dizziness,

headache, heavy head, etc)

8. Are you suffering from eye discomfort? (eg, soreness,

dryness, more tears, fuzzy, fatigue and more bloodshot eyes,

etc)

9. Do you suffer hearing system abnormalities? (eg, tinnitus,

hearing loss, earache, etc)

10. Do you have difficulty with your knees or with bending over?

11. Do you have any difficulty in climbing $3-5$ floors?

12. Do you have any difficulty in walking $1500 \mathrm{~m}$ ?

13. Could the fatigue be alleviated by rest?

$\square$ never $\square$ occasionally $\square$ sometimes $\square$ constantly $\square$ always

$\square$ never $\square$ occasionally $\square$ sometimes $\square$ constantly $\square$ always

$\square$ never $\square$ occasionally $\square$ sometimes $\square$ constantly $\square$ always

14. Do you have enough energy to cope with everyday life, work and learn?

15. You think you are in what physiological (physical) health status?

16. Do you have confidence?

17. Are you satisfied with your living conditions?

18. Are you optimistic about the future?

19. Are you feeling happy?

20. Do you feel nervous?

21. Do you experience bad moods or depression?

22. Do you feel insecure?

23. Do you have no reason to feel afraid?

24. Do you feel lonely?

25. Are you sensitive or suspicious?

26. How is your memory?

27. What about your ability to think and solve problems?

28. How is your psychological health (eg, emotional, cognitive ability) status?

29. Can you appropriately deal with unhappy events in your life, work and school?

30. Are you satisfied with your social relationships?

31. Are you satisfied with your performance in your life, work and school?

32. Can you quickly adapt to new living, working and learning environments?

33. Do you always keep in touch with friends and family (eg, visits, phone calls, other communications)?

34. Do you have friends to share your happiness and sadness?

35. Do you have many colleagues, classmates, neighbours, relatives or friends close to you?

36 . When you need help, would your family, colleagues or friends provide physical or emotional support or help?

37 . When you are in trouble, would you seek support and help from others?

38. What is the status of your social health (eg, interpersonal relationships, social interactions)?

39. What is the status of your health (including physiological, psychological and social aspects)?

\begin{tabular}{|c|c|c|c|c|}
\hline$\square$ never & $\square$ occasionally & $\square$ sometimes & $\square$ constantly & $\square$ always \\
\hline & alittle & $\square$ some & $\square$ hard & $\square$ very hard \\
\hline & Jlittle & $\square$ some & $\square$ hard & $\square$ very hard \\
\hline never & $\square$ little & $\square$ some & $\square$ hard & $\square$ very hard \\
\hline never & $\square$ occasionally & $\square$ sometimes & $\square$ constantly & $\square$ always \\
\hline never & $\square$ occasionally & $\square$ sometimes & $\square$ constantly & $\square$ always \\
\hline
\end{tabular}

$\square$ health $\square$ suboptimal health status $\square$ diseaseif you are in suboptimal health status, what's the extent: $\square$ mild $\square$ moderate $\square$ severe

nnever $\quad \square$ little $\quad \square$ some $\quad \square$ much $\quad \square$ quite

$\square$ never $\quad \square$ little $\quad \square$ general $\quad \square$ good $\quad \square$ very good

$\square$ never $\quad \square$ little $\square$ some $\quad \square$ much $\square$ quite

$\square$ never $\square$ occasionally $\square$ sometimes $\square$ constantly $\square$ always

$\square$ never $\square$ occasionally $\square$ sometimes $\square$ constantly $\square$ always

$\square$ never $\square$ occasionally $\square$ sometimes $\square$ constantly $\square$ always

$\square$ never $\square$ occasionally $\square$ sometimes $\square$ constantly $\square$ always

$\square$ never $\square$ occasionally $\square$ sometimes $\square$ constantly $\square$ always

$\square$ never $\square$ occasionally $\square$ some $\square$ much $\square$ quite

$\square$ never $\square$ occasionally $\square$ sometimes $\square$ constantly $\square$ always

$\square$ very poor $\square$ poor $\quad \square$ general $\square$ good $\square$ very good

$\square$ very poor $\square$ poor $\quad \square$ general $\square$ good $\square$ very good

$\square$ health $\square$ suboptimal health status $\square$ disease

if you are in suboptimal health status, what's the exten: $\square$ mild

$\square$ moderate $\square$ severe

$\square$ never $\square$ occasionally $\square$ sometimes $\square$ constantly $\square$ always

$\square$ never $\square$ rarely $\quad \square$ general $\quad \square$ good $\square$ very good

$\square$ never $\quad \square$ rarely $\quad \square$ general $\quad \square$ good $\quad \square$ very good

$\square$ never $\square$ occasionally $\square$ sometimes $\square$ constantly $\square$ always

$\square$ never $\square$ occasionally $\square$ sometimes $\square$ constantly $\square$ always

$\square$ never $\square$ few $\square$ some $\square$ many $\square$ very many,

more than 5

$\square$ few $\square$ some $\square$ many $\square$ very many,

$\square$ never $\square$ occasionally $\square$ sometimes $\square$ constantly $\square$ always

$\square$ never $\square$ occasionally $\square$ sometimes $\square$ constantly $\square$ always

$\square$ health $\square$ suboptimal health status $\square$ disease

if you are in suboptimal health status, what's the extent: $\square$ mild

$\square$ moderate $\square$ severe

$\square$ health $\square$ suboptimal health status $\square$ disease

if you are in suboptimal health status, what's the extent: $\square$ mild $\square$ moderate $\square$ severe 
Multiple assessments and informants may provide a richer and more thorough understanding of SHS.

Acknowledgements The Charlesworth Author Services Team edited the manuscript. The authors thank for their English editing and polishing services.

Contributors $R L$ and $X Z$ were involved in study concept and design, critical revision of the manuscript for important intellectual content and study supervision. JB, YH, YX, JC, FL, TW, JC, LW and YL were involved in acquisition of data. JB and $\mathrm{YH}$ were involved in analysis and interpretation of data and drafting of the manuscript. All authors were involved in the formulation of the research questions.

Funding This work was supported by the NSFC-Guangdong joint fund (No. U1132001), the National Science Foundation of China (Nos. 81173146 and 81373707), the Natural Science Foundation of Guangdong Province, China (Nos. S2012010009177 and S2011010002941), the Guangdong Provincial Department of Science and Technology and Guangdong Provincial Academy of Traditional Chinese Medicine joint fund (Nos. 2011B032200004 and 2012A032500004), the Guangdong Provincial Department of Science and Technology fund (Nos. 2011B031700018) and the Science and Technical Plan of Guangzhou, Guangdong, China (No. 2011J4300108).

Competing interests None.

Patient consent Obtained.

Ethics approval Ethics Committee of Nanfang Hospital in Guangzhou, China (2012) LunShenZi (No. 035).

Provenance and peer review Not commissioned; externally peer reviewed.

Data sharing statement No additional data are available.

Open Access This is an Open Access article distributed in accordance with the Creative Commons Attribution Non Commercial (CC BY-NC 4.0) license, which permits others to distribute, remix, adapt, build upon this work noncommercially, and license their derivative works on different terms, provided the original work is properly cited and the use is non-commercial. See: http:// creativecommons.org/licenses/by-nc/4.0/

\section{REFERENCES}

1. Wang W, Yan Y. Suboptimal health: a new health dimension for translational medicine. Clin Transl Med 2012;1:28.

2. Medicine CAOC. The TCM clinical guidelines of suboptimal health status. Beijing: China Press TCM, 2006.

3. Wang W, Russell A, Yan Y. Traditional Chinese medicine and new concepts of predictive, preventive and personalized medicine in diagnosis and treatment of suboptimal health. EPMA J 2014:5:4

4. Ke B, Liang Y. Anti-aging and complete suboptimal health checkup. Clin Funct Nutr 2011:3:137-40.

5. Dunstan RH, Sparkes DL, Roberts TK, et al. Development of a complex amino acid supplement, Fatigue Reviva, for oral ingestion: initial evaluations of product concept and impact on symptoms of suboptimal health in a group of males. Nutr $J$ 2013;12:115.

6. Davy CP, Patrickson M. Implementation of evidence-based healthcare in Papua New Guinea. Int J Evid Based Healthc 2012;10:361-8

7. Sun XM, Wei M, Zhu CY, et al. An investigation of suboptimal health status in Guangdong: a cross section study. Shandong Med $J$ 2008;48:59-60.

8. Mozaffarian D, Hao T, Rimm EB, et al. Changes in diet and lifestyle and long-term weight gain in women and men. $N$ Engl $J$ Med 2011;364:2392-404.

9. Lin $\mathrm{YH}$, Tsai EM, Chan TF, et al. Health promoting lifestyles and related factors in pregnant women. Chang Gung Med $J$ 2009;32:650-61.

10. Kastorini CM, Milionis HJ, Esposito K, et al. The effect of mediterranean diet on metabolic syndrome and its components: a meta-analysis of 50 studies and 534,906 individuals. J Am Coll Cardiol 2011;57:1299-313

11. Mozaffarian D, Capewell S. United Nations' dietary policies to prevent cardiovascular disease. BMJ 2011:343:d5747.

12. Walker SN, Sechrist KR, Pender NJ. The health-promoting lifestyle profile: development and psychometric characteristics. Nurs Res 1987;36:76-81.
13. Al-Kandari F, Vidal VL. Correlation of the health-promoting lifestyle, enrollment level, and academic performance of College of Nursing students in Kuwait. Nurs Health Sci 2007;9:112-19.

14. Bagwell MM, Bush HA. Health conception and health promotion in blue collar workers. Program planning issues. AAOHN J 1999:47:512-18.

15. Teng HL, Yen M, Fetzer S. Health promotion lifestyle profile-II: Chinese version short form. J Adv Nurs 2010;66:1864-73.

16. Sohng KY, Sohng S, Yeom HA. Health-promoting behaviors of elderly Korean immigrants in the United States. Public Health Nurs 2002;19:294-300

17. Riffle KL, Yoho J, Sams J. Health-promoting behaviors, perceived social support, and self-reported health of Appalachian elderly. Public Health Nurs 1989;6:204-11.

18. Bagwell MM, Bush HA. Improving health promotion for blue-collar workers. J Nurs Care Qual 2000;14:65-71.

19. Xiao YY, Liu LK, Zhang Q, et al. An investigate on fatigue in railway medical school student and analysis of its related factors. Mod Prev Med 2006;33:1091-2.

20. Yan YX, Liu YQ, Li M, et al. Development and evaluation of a questionnaire for measuring suboptimal health status in urban Chinese. J Epidemiol 2009;19:333-41.

21. Chen J, Li J, Yu BY, et al. Mental subhealth among high-grade medical undergraduate students. J Clin Rehabil Tissue Eng Res 2007:11:9962-5.

22. Qiang L, Xiumin Z, Jinghua L, et al. Investigation and analysis of suboptimal health status influencing factors in community inhabitants of Shenyang city. Med Soc 2010;2:33-5.

23. Jun XU, Li-yi F, Ren L, et al. Assessment of the reliability and validity of the Suboptimal Health Measurement Scale Version 1.0. J S Med U 2011;31:33-8.

24. Yang XL. Suboptimal health status and related factors of medical undergraduate students. Chin J Public Health 2007;23:378-9.

25. Fan CX, Ma XB, Wang HS, et al. Suboptimal health status and related factors of undergraduate students in Guang Zhou. Chin $J$ Public Health 2005;21:390-1.

26. Grad FP. The preamble of the constitution of the World Health Organization. Bull World Health Organ 2002;80:981-4.

27. Wang YX. Sub-health-new concept of health in the 21st century. Jiangxi: Jiangxi Science and Technology Press, 2002.

28. Cao H, Sun Y, Wan $Y$, et al. Problematic internet use in Chinese adolescents and its relation to psychosomatic symptoms and life satisfaction. BMC Public Health 2011;11:802.

29. Gastard J, Gosselin M, Bretagne JF. Gastroduodenal ulcer and psychology. Ann Gastroenterol Hepatol (Paris) 1986;22:131-40.

30. Ceuppens J. Western lifestyle, local defenses and the rising incidence of allergic rhinitis. Acta Otorhinolaryngol Belg 2000;54:391-5.

31. Haug E, Rasmussen M, Samdal O, et al. Overweight in school-aged children and its relationship with demographic and lifestyle factors: results from the WHO-Collaborative Health Behaviour in School-aged Children (HBSC) study. Int J Public Health 2009;54 (Suppl 2):167-79.

32. Bradshaw PT, Siega-Riz AM, Campbell M, et al. Associations between dietary patterns and head and neck cancer: the Carolina head and neck cancer epidemiology study. Am J Epidemiol 2012;175:1225-33.

33. Tao MH, Shu XO, Ruan ZX, et al. Association of overweight with breast cancer survival. Am J Epidemiol 2006;163:101-7.

34. Cote AT, Harris KC, Panagiotopoulos C, et al. Childhood obesity and cardiovascular dysfunction. J Am Coll Cardiol 2013;62:1309-19.

35. Ornish D, Lin J, Daubenmier J, et al. Increased telomerase activity and comprehensive lifestyle changes: a pilot study. Lancet Oncol 2008:9:1048-57.

36. Davis NJ, Ma Y, Delahanty LM, et al. Predictors of sustained reduction in energy and fat intake in the Diabetes Prevention Program Outcomes Study intensive lifestyle intervention. J Acad Nutr Diet 2013;113:1455-64.

37. Sone $\mathrm{H}$, Tanaka $\mathrm{S}$, limuro $\mathrm{S}$, et al. Long-term lifestyle intervention lowers the incidence of stroke in Japanese patients with type 2 diabetes: a nationwide multicentre randomised controlled trial (the Japan Diabetes Complications Study). Diabetologia 2010;53:419-28.

38. Yan YX, Dong J, Liu YQ, et al. Association of suboptimal health status and cardiovascular risk factors in urban Chinese workers. $J$ Urban Health 2012;89:329-38.

39. Romero-Acosta K, Canals J, Hernandez-Martinez C, et al. Age and gender differences of somatic symptoms in children and adolescents. J Ment Health 2013;22:33-41.

40. McGuinness TM, Dyer JG, Wade EH. Gender differences in adolescent depression. J Psychosoc Nurs Ment Health Serv 2012;50:17-20. 